\title{
Faecal bile acid loss and bile acid pool size during short-term treatment with ursodeoxycholic and chenodeoxycholic acid in patients with radiolucent gallstones
}

\author{
G. SALVIOLI ${ }^{1}$ AND R. SALATI \\ From the Department of Clinical Medicine, University of Modena, Modena, Italy
}

SUMMARY Twelve non-obese patients with radiolucent gallstones were fed on a standard diet. After 10 days (period A), six patients received $15 \mathrm{mg} / \mathrm{kg}$ /day of ursodeoxycholic acid (UDCA) (group I) and the other six (group II) the same dose of chenodeoxycholic acid (CDCA) for 15 days (period B). An intravenous injection of $20 \mu \mathrm{Ci}$ of ${ }^{14} \mathrm{C}$-UDCA and of ${ }^{14} \mathrm{C}-\mathrm{CDCA}$ was given on the 11 th day of period B to the patients of group I and II respectively. Stools were collected at the end of period A and $B$ and one bile sample was collected on the 12th day of period B. The faecal bile acid loss was higher during chenotherapy $(36 \cdot 12 \mu \mathrm{mol} / \mathrm{kg} /$ day) than during ursotherapy $(23.94 \mu \mathrm{mol} / \mathrm{kg} / \mathrm{day})$, as was the proportion of lithocholic acid $(73 \%$ vs $43 \%)$ in the faeces. Decay constant rate of faecal radioactivity was 0.365 day $^{-1}$ in group I and 0.642 in group II. The results indicate that faecal bile acid excretion and turnover rate are greater during CDCA than UDCA, while UDCA increases the bile acid pool size to an even greater extent than does CDCA $(150.2$ vs $94.9 \mu \mathrm{mol} / \mathrm{kg})$. This is probably because the former is more slowly degraded to poorly reabsorbable compounds. In fact, the bile saturation index was 0.66 in group I and 1.05 in group II, even though biliary CDCA in the latter had risen to $69 \cdot 6 \%$.

Ursodeoxycholic acid (UDCA), the 7ßepimer of chenodeo: ycholic acid (CDCA), decreases the saturation of bile with cholesterol (Makino et al., 1975) and dissolves cholesterol gallstones using one-half tc two-thirds of the doses normally used for chenoth erapy (Maton et al., 1977; Salvioli et al., 1977; Mak no and Nakagawa, 1978). The fact that the intestir al metabolism of cheno and urso are different mily be the cause of their different efficacies -for example, in vitro the $7 \beta \mathrm{OH}$ group is more slowly degraded by intestinal bacteria than is the $7 \alpha \mathrm{OH}$ group, so that UDCA is less degraded to lithocholic acid (LCA) than is CDCA (Fedorowski et al., 1977a). The in vivo importance of such observations in the effectiveness of UDCA therapy is not known.

In the present study we have examined the effects of short-term feeding of UDCA and CDCA on (1) the bile acid pool size, and (2) faecal bile acid loss, on the assumption that the faecal excretion of bile acids indicates their fractional turnover rate.

${ }^{1}$ Address for correspondence: G. Salvioli, MD, Department of Clinical Medicine, Via del Pozzo, 7141100 Modena, Italy. Received for publication 28 March 1979

\section{Methods}

Reference compounds (unconjugated and conjugated bile acids) were supplied from Supelco, Inc. ${ }^{24-{ }^{14} \mathrm{C} \text { - }}$ CDCA and $24-{ }^{14} \mathrm{C}$-UDCA were purchased from Radio chemical Centre, Amersham; the radiochemical purity was shown to be greater than $98 \%$ by thin-layer chromatography (TLC). The UDCA and CDCA administered to patients were supplied by Zambon spa (Bresso, Italy). The enzymatic reagent kit for fluorimetric determination of total bile acids was supplied by Nyegaard \& Co, A/S, Oslo. Sulphated lithocholic acid and sulphated tauro- and glycolithocholic acid were synthesised according to the method of Eyssen et al. (1976) and each was purified by TLC (solvent system chloroform:methanol:acetic acid:water 65:24:15:4 by volume) (Cass et al., 1975).

\section{PROTOCOL}

Twelve non-obese inpatients (seven women and five men) with radiolucent gallstones were fed during the study on a standard diet ( 30 calories $/ \mathrm{kg}$ :carbohydrates, $52 \%$; lipids, $27 \%$; and protein, $21 \%$ ), containing $500 \mathrm{mg} /$ day of $\mathrm{Cr}_{2} \mathrm{O}_{3}$ as an inert marker 
(Bolin et al., 1952). The daily cholesterol intake was about $500 \mathrm{mg}$. After 10 days (period A) six patients (group I) received UDCA $(15 \mathrm{mg} / \mathrm{kg} /$ day $)$ for 15 days (period $B$ ) and an intravenous infusion of 20 $\mu \mathrm{Ci}{ }^{14} \mathrm{C}-$ UDCA on the 11 th day of the period $\mathrm{B}$. The other six patients (group II) received CDCA and an infusion of ${ }^{14} \mathrm{C}-\mathrm{CDCA}$ at the same doses. Bile samples were collected one day after the injection with labelled bile acid in order to determine the bile acid pool, bile acid composition, and the saturation index. Stools were collected and weighed on the last three days of period $\mathrm{A}$ and on the last five days of period $B$; the samples were stored at $-20^{\circ} \mathrm{C}$ until analysed. No antibiotics were given during the course of the study.

QUANTIFICATION OF BILE ACID POOL SIZE

AND SATURATION INDEX

The bile acid pool size was measured according to the one-day method of Duane et al. (1975). Fasting bile samples were obtained with a single-lumen polyvinyl tube positioned radiographically in the descending portion of the duodenum; gallbladder contraction was stimulated by intravenous cerulein $0.1 \mu \mathrm{g} / \mathrm{kg}$ (Farmitalia, Milan). Only a small aliquot $(<5 \%$ of the total aspirate) of bile-rich duodenal aspirate was used and the remainder was returned via the tube. Bile acid mass and radioactivity were determined from a corresponding aliquot of methanolic extracts of bile. The biliary lipid composition (cholesterol, phospholipids, and bile salts) was expressed in molar percent and the saturation index (SI) was calculated from polynomial equation (Thomas and Hofmann, 1973) describing the cholesterol solubility line proposed by Hegardt and Dam (1971). The saturation index was not corrected according to the correction factor deveioped by Carey (1978) for UDCA-rich bile.

Biliary bile acid composition was determined by gas liquid chromatography (GLC); $0.05 \mathrm{ml}$ of bile was hydrolysed with cholyl glycine hydrolase (Sigma Chemical Co.) for three hours at $37^{\circ} \mathrm{C}$ in buffer acetate $\mathrm{pH} 5 \cdot 6$. The internal standard $(3 \alpha 12 \alpha$ dihydroxy-7-one- 5 Bcholan-24oic acid) was added after hydrolysis. The incubation mixture was acidified to $\mathrm{pH} 1$ and the bile acids extracted with $3 \times 50 \mathrm{ml}$ diethyl ether. The combined extracts, dried in vacuo, were methylated with an excess of diazomethane for 15 minutes; the analysis was carried out on Packard-Becker 420 dual flame ionisation detector instrument, using $2 \mathrm{~m} \times 3 \mathrm{~mm}$ i.d. glass column (U shaped) packed with QF-1 $3 \%$ on Gas-Chrom 100-200 mesh, kept at $220^{\circ} \mathrm{C}$; the injection and detector temperature were $235^{\circ} \mathrm{C}$ and $245^{\circ} \mathrm{C}$ respectively.
EXTRACTION OF BILE ACIDS FROM

FAECAL SAMPLES

Faeces were homogenised with a known amount of saline; $5 \mathrm{ml}$ of faecal homogenates were refluxed for one hour at $70^{\circ} \mathrm{C}$ with $\mathrm{NaOH} 100 \mathrm{mmol}$ in ethanol $70 \%$. After cooling, $50 \mathrm{ml}$ petroleum ether was added three times in order to extract the neutral sterols. The lower ethanolic phase was evaporated and the bile salt extracted with $5 \mathrm{~g}$ Amberlite



Figure Flow chart showing the methods of determining the faecal bile acid content, composition, and radioactivity after UDCA and CDCA administration.

XAD-2 by a batch procedure (Van Berge Henegouwen and Hofmann, 1976). The elution of bile acids and their derivatives was obtained with two $35 \mathrm{ml}$ hot methanol washes. An aliquot of methanolic phase was used for measuring total radioactivity (Figure). $\mathrm{Cr}_{2} \mathrm{O}_{3}$ was determined on faecal sample aliquots according to the method of Bolin et al. (1952).

SEPARATION OF SULPHATED AND

NON-SULPHATED BILE ACIDS

The purified bile acid extracts were separated on a Sephadex LH-20 column (Figure) into two fractions of different polarities: the first fraction, eluted with $70 \mathrm{ml}$ chloroform:methanol $1: 1$ containing 0.01 $\mathrm{M} \mathrm{NaCl}$, contained unconjugated bile acids (fraction I); the second fraction, eluted with $60 \mathrm{ml}$ methanol, contained sulphated bile acids (fraction II). Because the sulphate fraction can be contaminated by trace amounts of non-sulphates, the efficacy of the separation was checked by rechromatography of the sulphate fraction on Sephadex LH-20. Total bile acids of fraction I and II (after solvolysis as desscribed below) were determined with an enzymatic method and results were corrected daily for faecal flow by reference to the excretion of the inert marker chromic oxide (Davignon et al., 1968). 
ANALYSIS OF BILE ACID COMPOSITION OF FAECES

The faecal bile acid molar percentage of the second and third day stool samples of period A and B was determined by GLC as above. If fraction I is acidified and extracted with diethylether, it is possible to measure the percentage of unconjugated bile acids in faeces. According to this test, fraction I contained only a small amount of conjugated bile acids. This agrees with the analysis carried out on silica gel plates, developed in the system isooctane:isopropylether:acetic acid (50:25:25). Fraction II was subjected to solvolysis for 24 hours with acetone: methanol: $\mathrm{HCl} 10 \mathrm{~N}(9: 1: 0 \cdot 1)$ at $37^{\circ} \mathrm{C}$ in order to cleave sulphate esters: the resulting mixture, neutralised with $\mathrm{NH}_{4} \mathrm{OH}$, was purified and desalted by Amberlite XAD-2 batch. Bile acids in the extracts thus obtained were quantified using the enzymatic method. Qualitative examination by TLC demonstrated that the extracts contained only nonsulphated bile acids. At the beginning of the procedure $5 \mu \mathrm{Ci}$ of ${ }^{14} \mathrm{C}-\mathrm{CDCA}$ were added to faecal samples of period A only, in order to check the efficiency of the extraction. The mean recovery of added CDCA was $92.6 \pm 3.8 \%$ after the purification on Amberlite and $79.7 \pm 7.6$ after column chromatography and enzymatic hydrolysis.

\section{MEASUREMENT OF RADIOACTIVITY}

Total radioactivity was estimated on day $1,2,3,4$, and 5 after labelled injection using the method as below. Daily excretion rate of ${ }^{14} \mathrm{C}$, relatively to the $\mathrm{Cr}_{2} \mathrm{O}_{3}$ mass intake and excretion, was expressed according to the formula of Stanley and Nemchausky (1967). The decay constant $\left(\mathrm{day}^{-1}\right)$ of ${ }^{14} \mathrm{C}-\mathrm{CDCA}$ and ${ }^{14} \mathrm{C}$-UDCA was determined using a singlecompartment kinetic model (Lindstedt, 1957).

The distribution of radioactivity in the different bile acids (cholic, CDCA, UDCA, deoxycholic, LCA, and 7 ketolithocholic acid) identified by reference to known standards run in parallel, was determined by TLC on the bands which were visualised by spraying with Bili Spra (8-hydroxyl pyrenetrisulfonic acid salt) (Supelco, Inc., Bellafonte, $\mathrm{Pa}$.) and scraped off the plates, using a liquid scintillation counter; quenching was estimated by adding ${ }^{14} \mathrm{C}$-hexadecane as internal standard to the counting vials. This procedure was carried out only on the second day stool sample.

\section{STATISTICAL ANALYSIS}

The statistical significance of the differences between values obtained in groups I and II and during periods $A$ and $B$ was tested using the non-paired Student's $t$ test.

\section{Results}

\section{BILE ACID COMPOSITION}

The mean saturation index was lower in the group treated with UDCA (SI 0.66) than in the group taking CDCA (Table 1). The bile acid pool size was greater in UDCA-treated patients $(150 \mu \mathrm{mol} / \mathrm{kg})$ with respect to the group receiving CDCA (94 $\mu \mathrm{mol} / \mathrm{kg}$ ); the difference was statistically significant. The percentage composition of biliary bile acids after 10 days of treatment is shown in Table 2: the

Table 1 Biliary lipid composition, saturation index $(S I)$ and bile acid pool size in patients taking urso (group I) or cheno (group II)

\begin{tabular}{|c|c|c|c|c|c|c|}
\hline \multirow[t]{2}{*}{ Subjects } & \multirow{2}{*}{$\begin{array}{l}\text { Weight } \\
(k g)\end{array}$} & $P L$ & $\mathrm{CHO}$ & $B S$ & \multirow[t]{2}{*}{$S I$} & \multirow{2}{*}{$\begin{array}{l}\text { Bile acid pool size } \\
(\mu \mathrm{mol} / \mathrm{kg})\end{array}$} \\
\hline & & \multicolumn{3}{|c|}{ (molar \%) } & & \\
\hline 1 & 63 & $20 \cdot 7$ & $2 \cdot 8$ & $76 \cdot 5$ & 0.53 & 130.5 \\
\hline 2 & 72 & 18.9 & $3 \cdot 7$ & $77 \cdot 4$ & 0.63 & $145 \cdot 0$ \\
\hline 3 & 64 & $14 \cdot 8$ & $5 \cdot 1$ & $80 \cdot 1$ & 1.01 & $150 \cdot 7$ \\
\hline 4 & 68 & $23 \cdot 8$ & 3.8 & $72 \cdot 4$ & 0.54 & 155.0 \\
\hline 6 & 51 & $15 \cdot 8$ & $3 \cdot 6$ & 80.6 & 0.69 & $160 \cdot 8$ \\
\hline Mean & & & & & 0.66 & $150 \cdot 2$ \\
\hline$\pm \mathrm{SD}$ & & & & & $0 \cdot 18$ & $11 \cdot 2$ \\
\hline \multicolumn{7}{|l|}{ Group II } \\
\hline 1 & 72 & 16.4 & 3.9 & $79 \cdot 7$ & 0.73 & $97 \cdot 0$ \\
\hline 2 & 64 & $17 \cdot 1$ & $5 \cdot 7$ & $77 \cdot 2$ & $1 \cdot 00$ & $102 \cdot 2$ \\
\hline 3 & 78 & $19 \cdot 8$ & $7 \cdot 6$ & $72 \cdot 6$ & $1 \cdot 21$ & $73 \cdot 2$ \\
\hline 4 & 64 & $17 \cdot 4$ & $6 \cdot 8$ & $75 \cdot 8$ & $1 \cdot 19$ & $100 \cdot \overline{2}$ \\
\hline 6 & 66 & $21 \cdot 2$ & $6 \cdot 7$ & $72 \cdot 1$ & $1 \cdot 04$ & $91 \cdot 2$ \\
\hline Mean & & & & & $1.05 \dagger$ & $94.9 *$ \\
\hline$\pm \mathrm{SD}$ & & & & & $0 \cdot 17$ & $11 \cdot 7$ \\
\hline
\end{tabular}

PL: phospholipids. CHO: cholesterol. BS: bile salts.

${ }_{\mathrm{P}}<0.001$ between group I and II; $\nmid \mathrm{P}<0.01$ between group I and II. 
Table 2 Effect of ursodeoxycholic acid and chenic acid treatment on biliary bile acid composition

\begin{tabular}{lcrrrr}
\hline & $L C A$ & $D C A$ & $C D C A$ & UDCA & \multicolumn{1}{c}{$C A$} \\
\cline { 2 - 6 } & \multicolumn{1}{l}{ (molar \%) } & & & \\
\hline Group I & 1.8 & 10.8 & 15.9 & 53.7 & 17.8 \\
Group II & \pm 0.7 & \pm 1.7 & \pm 5.7 & \pm 8.9 & \pm 2.4 \\
& 4.7 & 7.8 & 69.6 & 3.8 & 14.1 \\
& \pm 0.9 & \pm 1.6 & \pm 8.5 & \pm 0.3 & \pm 2.3 \\
\hline
\end{tabular}

percentage of lithocholic acid was higher in group II where CDCA became the major bile acid; in group I, although UDCA was the major bile acid fraction, CDCA and cholic acid were well represented.

\section{FAECAL BILE ACID EXCRETION}

The daily faecal bile acid loss, corrected by reference to the daily excretion of the inert marker $\mathrm{Cr}_{2} \mathrm{O}_{3}$, is reported in Table 3. During treatment the faecal bile acid loss grew to $23.94 \mu \mathrm{mol} / \mathrm{kg} /$ day in the group receiving UDCA and to $36 \cdot 12 \mu \mathrm{mol} / \mathrm{kg} /$ day in the group treated with CDCA.

\section{SULPHATED AND NON-SULPHATED BILE}

ACID IN FAECES

The mass of sulphated faecal bile acid amounted to $13.5 \%$ and to $10.3 \%$ of total bile acid in period $\mathrm{A}$
Table 3 Sulphated and non-sulphated bile acids excreted with faeces before (period $A$ ) and during (period B) UDCA (group I) or CDCA (group II) administration

\begin{tabular}{lccc}
\hline Group & Period & Non-sulphated & Sulphated \\
\cline { 3 - 4 } & & $(\mu \mathrm{mol} / \mathrm{kg} /$ day $)$ & \\
\hline \multirow{3}{*}{ I } & A & 8.12 & $1 \cdot 27$ \\
& & 2.02 & \pm 0.21 \\
& B & $19 \cdot 77^{*}$ & $4 \cdot 17^{*}$ \\
& & \pm 3.27 & \pm 0.65 \\
II & A & 7.85 & 0.91 \\
& & \pm 2.22 & \pm 0.17 \\
& B & $28.07 \dagger \ddagger$ & $8.05 \dagger \ddagger$ \\
& & \pm 5.07 & \pm 0.40 \\
\hline
\end{tabular}

${ }^{*} \mathrm{P}<0.01$ between $\mathrm{A}$ and $\mathrm{B}$ of both groups $\mathrm{I}$ and II. $+\mathrm{P}<0.01$ between the two period Bs. $\ddagger P<0.001$ between $A$ and $B$ of group II.

for groups I and II respectively. The percentage rose to 17.4 during ursotherapy and to 22.3 during chenotherapy (Table 3 ).

BILE ACID PATTERN IN FAECES

The composition of the non-sulphated fraction was very similar to that of the sulphated fraction (Table 4); LCA percentage was higher in patients taking

Table 4 Faecal bile acid composition before (period A) and during (period B) UDCA (group I) and CDCA ( group II) administration

\begin{tabular}{|c|c|c|c|c|c|c|c|c|}
\hline \multirow[t]{2}{*}{ Period } & \multirow[t]{2}{*}{ Fraction } & $L C A$ & $D C A$ & $C D C A$ & $U D C A$ & $7 K L C A$ & $C A$ & Others \\
\hline & & \multicolumn{7}{|l|}{ (molar \%) } \\
\hline \multicolumn{9}{|l|}{ Group I } \\
\hline & $\mathbf{S}$ & $\begin{array}{r}45 \cdot 6 \\
\pm 10 \cdot 5\end{array}$ & $\begin{array}{r}39.6 \\
\pm 7.6\end{array}$ & $\begin{array}{r}3 \cdot 7 \\
\pm 1 \cdot 1\end{array}$ & $\begin{array}{r}1 \cdot 2 \\
\pm 0.3\end{array}$ & $\mathbf{t r}$ & $\begin{array}{r}1 \cdot 2 \\
\pm 0.3\end{array}$ & $\begin{array}{r}8.0 \\
\pm \quad 3.2\end{array}$ \\
\hline \multirow{2}{*}{$\mathbf{A}$} & NS & $\begin{array}{r}41 \cdot 4 \\
\pm 9 \cdot 4\end{array}$ & $\begin{array}{r}37 \cdot 2 \\
\pm \quad 9 \cdot 2\end{array}$ & $\begin{array}{r}5.6 \\
\pm 1.7\end{array}$ & $\begin{array}{r}3.2 \\
\pm 1.5\end{array}$ & $\begin{array}{r}1.2 \\
\pm 0.4\end{array}$ & $\begin{array}{r}0.8 \\
\pm \quad 0 \cdot 1\end{array}$ & $\begin{array}{r}10.2 \\
\pm \quad 3.9\end{array}$ \\
\hline & $\mathbf{S}$ & $\begin{array}{r}44.6 \\
\pm 12.2\end{array}$ & $\begin{array}{r}36.5 \\
\pm \quad 7.9\end{array}$ & $\begin{array}{r}3.4 \\
\pm 0.6\end{array}$ & $\begin{aligned} & 5 \cdot 6^{*} \\
\pm & 0.8\end{aligned}$ & $\operatorname{tr}$ & $\operatorname{tr}$ & $\begin{array}{r}9 \cdot 5 \\
\pm \quad 3 \cdot 2\end{array}$ \\
\hline B & NS & $\begin{array}{r}37.7 \\
\pm \quad 8.7\end{array}$ & $\begin{array}{r}29 \cdot 1 \\
\pm \quad 6 \cdot 1\end{array}$ & $\begin{array}{l}10.5 \dagger \\
\pm 2.2\end{array}$ & $\begin{aligned} & 9 \cdot 4 \ddagger \\
\pm & 2 \cdot 0\end{aligned}$ & $\begin{array}{l}4 \cdot 7 \ddagger \\
\pm 1 \cdot 4\end{array}$ & $\begin{array}{r}1 \cdot 1 \\
\pm 0 \cdot 1\end{array}$ & $\begin{array}{r}7.2 \\
\pm 4.6\end{array}$ \\
\hline \multicolumn{9}{|l|}{ Group II } \\
\hline \multirow{3}{*}{$\mathbf{A}$} & $\mathbf{S}$ & $\begin{array}{r}45.4 \\
\pm 12.8\end{array}$ & $\begin{array}{r}37.4 \\
\pm \quad 7.6\end{array}$ & $\begin{array}{r}4.6 \\
\pm \quad 0.8\end{array}$ & $\begin{array}{r}1.0 \\
\pm 0.2\end{array}$ & tr & $\begin{array}{r}1 \cdot 1 \\
\pm \quad 0 \cdot 3\end{array}$ & $\begin{array}{r}9.1 \\
\pm \quad 3.8\end{array}$ \\
\hline & NS & $\begin{array}{r}38 \cdot 5 \\
\pm \quad 6.8\end{array}$ & $\begin{array}{r}39 \cdot 6 \\
\pm \quad 5.9\end{array}$ & $\begin{array}{r}7.4 \\
\pm \quad 2.0\end{array}$ & $\begin{array}{r}2.6 \\
\pm \quad 0.8\end{array}$ & $\begin{array}{r}1.5 \\
\pm 0.3\end{array}$ & $\begin{array}{r}1.4 \\
\pm 0.4\end{array}$ & $\begin{array}{r}8 \cdot 2 \\
+\quad 2 \cdot 7\end{array}$ \\
\hline & $\mathbf{s}$ & $\begin{array}{l}76 \cdot 8 * \ddagger \\
\pm 12 \cdot 6\end{array}$ & $\begin{array}{ll} & 3.8^{*} \ddagger \\
\pm & 1.6\end{array}$ & $\begin{array}{c}12.4 \dagger \\
\pm 3.4\end{array}$ & $\begin{array}{r}2 \cdot 2 \\
\pm 0.7\end{array}$ & $\mathbf{t r}$ & $\operatorname{tr}$ & $\begin{array}{r}4.7 \\
+\quad 1.8\end{array}$ \\
\hline B & NS & $\begin{aligned} & 70 \cdot 4^{*} \\
& \pm 13.8\end{aligned}$ & $\begin{array}{ll} & 8 \cdot 5^{*} \\
\pm & 3 \cdot 1\end{array}$ & $\begin{array}{r}9.7 \\
\pm \quad 1.9\end{array}$ & $\begin{array}{r}1.7 \\
\pm 0.4\end{array}$ & $\begin{array}{r}2 \cdot 7 \\
\pm \quad 0.8\end{array}$ & $\begin{array}{r}0.5 \\
\pm 0.2\end{array}$ & $\begin{array}{r}5.1 \\
\pm \quad 2.3\end{array}$ \\
\hline
\end{tabular}

${ }^{*} \mathbf{P}<0.001$ between period $A$ and $B$.

$+P<0.01$ between period $A$ and $B$.

$\mp \mathbf{P}<0.001$ between period B of group I and period B of group II.

S: sulphated. NS: non-sulphated.

Group I received UDCA, group II CDCA. 
Table 5 Decay constant rate of faecal radioactivity and stool weight in patients taking UDCA (group I) or CDCA (group II)

\begin{tabular}{|c|c|c|}
\hline Subjects & $\begin{array}{l}\text { Decay constant rate } \\
(\text { day-1) }\end{array}$ & $\begin{array}{l}\text { Stool weight } \\
\text { (g/day) }\end{array}$ \\
\hline \multicolumn{3}{|l|}{ Group I } \\
\hline 1 & 0.358 & 125 \\
\hline 2 & 0.403 & 95 \\
\hline 3 & 0.364 & 106 \\
\hline 4 & 0.401 & 132 \\
\hline 5 & 0.324 & 98 \\
\hline 6 & 0.345 & 106 \\
\hline Mean & 0.365 & $110 \cdot 3$ \\
\hline \pm SD & 0.031 & $14 \cdot 2$ \\
\hline \multicolumn{3}{|l|}{ Group II } \\
\hline 1 & 0.624 & 174 \\
\hline 2 & 0.480 & 108 \\
\hline 3 & 0.762 & 156 \\
\hline 4 & 0.490 & 110 \\
\hline 5 & 0.796 & 135 \\
\hline 6 & 0.705 & 150 \\
\hline Mean & $0.642^{*}$ & $138 \cdot 8$ \\
\hline$\pm \mathbf{S D}$ & 0.135 & $26 \cdot 2$ \\
\hline
\end{tabular}

$* \mathbf{P}<0.001$.

Stool weight is the mean value over a period of five days.

CDCA in both the sulphated and non-sulphated fractions.

\section{FAECAL RADIOACTIVITY}

The time course of faecal excretion of ${ }^{14} \mathrm{C}$ after intravenous injection of ${ }^{14} \mathrm{C}$-UDCA and ${ }^{14} \mathrm{C}$-CDCA is shown in Table 5; the decrease of radioactivity remaining in the body was more rapid in patients taking CDCA. The decay constant was 0.365 day $^{-1}$ in group I and 0.642 in group II; the differences were statistically significant. Such changes occurred independently of any significant variation in stool weight. The stool weights before treatment (mean of three days) were 116.4 \pm 15.5 in group I and 128.6 \pm $19 \cdot 7$ (g/day) in group II.

Table 6 shows the distribution of radioactivity in the faecal bile acids of groups I and II the second day after the injection of labelled bile acids. The proportion of radioactivity found in the LCA fraction was greater in group II than in group I. During the following days the proportion of LCA radioactivity increased in group $I$ also.

A portion of injected UDCA was excreted unchanged and $12.1 \%$ of total radioactivity was present in 7 keto LCA. The percentage of total radioactivity was higher in the non-sulphated fraction both in group $I(87.6 \% \pm 17 \cdot 4)$ and in group II $(81 \cdot 5 \pm 19 \cdot 3)$.

\section{Discussion}

The results of this short-term study confirm in vivo the previous findings of Fedorowski et al. (1977a) that UDCA is more slowly degraded than is CDCA and that less LCA is formed by bacteria enzymes from UDCA. More faecal bile acid are excreted during short-term chenotherapy than during ursotherapy, the ${ }^{14} \mathrm{C}$ retention being larger in the UDCA treated group given ${ }^{14} \mathrm{C}$-UDCA than in the CDCA group given ${ }^{14} \mathrm{C}-\mathrm{CDCA}$. For these reasons the pool size may become greater after 10 days of ursotherapy than after the same period of chenotherapy. The study was a deliberately short-term one, so that patients could be followed in hospital during the experiment.

\section{BILIARY LIPID COMPOSITION}

Even though the cholesterol saturation index at the end of period $A$ has not been determined, its value after treatment is lower in patients taking UDCA. From one to four weeks of treatment with CDCA are required for patients with cholesterol gallstones to produce an unsaturated bile (Iser et al., 1977). The bile desaturating capacity of UDCA appears to be greater than that of CDCA. In the experience of Maton et al. (1977) a dose of $5 \mathrm{mg} / \mathrm{kg} / \mathrm{day}$ of UDCA is sufficient to desaturate bile.

Bile acid pool size is greater in group I; in fact, during chenotherapy, the change in bile acid pool size is due to the increase in the CDCA pool and to the considerable decrease in the cholic and deoxycholic acid pools (Danzinger et al., 1973). During ursotherapy the pool size increases because CDCA, deoxycholic and cholic acids are slightly decreased and UDCA represent more than half the pool.

FAECAL BILE ACID LOSS

The mass of total bile acids in faeces is measured

Table 6 Distribution of radioactivity in faecal bile acids of sulphated $(S)$ and non-sulphated $(N S)$ fraction two days after the injection of labelled UDCA or CDCA

\begin{tabular}{|c|c|c|c|c|c|c|}
\hline & & \multicolumn{5}{|c|}{ On second day } \\
\hline & & $L C A$ & $C D C A$ & $U D C A$ & 7 keto LCA & Others \\
\hline Group I & $\begin{array}{l}\mathbf{N S} \\
\mathbf{S}\end{array}$ & $\begin{array}{l}35 \cdot 6 \\
48 \cdot 7\end{array}$ & $\begin{array}{l}10 \cdot 5 \\
10 \cdot 4\end{array}$ & $\begin{array}{l}21 \cdot 7 \\
17 \cdot 2\end{array}$ & $\begin{array}{l}12 \cdot 1 \\
\operatorname{tr}\end{array}$ & $\begin{array}{l}20 \cdot 1 \\
23 \cdot 4\end{array}$ \\
\hline Group II & $\begin{array}{l}\text { NS } \\
\mathbf{S}\end{array}$ & $\begin{array}{l}62 \cdot 4 \\
72 \cdot 0\end{array}$ & $\begin{array}{l}17.6 \\
16.3\end{array}$ & $\begin{array}{l}5 \cdot 1 \\
2 \cdot 5\end{array}$ & $\begin{array}{l}3 \cdot 1 \\
1 \cdot 1\end{array}$ & $\begin{array}{l}7 \cdot 8 \\
6 \cdot 1\end{array}$ \\
\hline
\end{tabular}


using an enzymatic method which therefore does not estimate the bile acid conjugated at the C-3 position. However, if solvolysis is carried out, the detection of bile acids is complete, as the 3 hhydroxy bile acids do not have quantitative importance, as they represent only $4-5 \%$ of total faecal bile acids (Subbiah et al., 1973). The faecal bile acid loss is higher in patients given CDCA than UDCA. Although the results refer to a non-steady state equilibrium, they indicate that CDCA is eliminated more rapidly in the intestine. The mechanism for the more rapid elimination of CDCA than UDCA is not known. It is unlikely that rapid intestinal transit plays an important role, as faecal bile acid excretion increases only slightly when intestinal transit time is shortened by the oral administration of mannitol (Meihoff and Kern, 1968).

The increased percentage of LCA and sulphated products in the faeces of patients taking CDCA is consonant with the higher faecal bile acid excretion. With regard to the presence of bile acid sulphated in the human faeces, Podesta et al. (1978) reported that this fraction accounted for $27.4 \%$ of total bile acids in control subjects, and $25-60 \%$ and $17-22.5 \%$ in patients given UDCA and CDCA respectively. Intestinal flora such as Pseudomonas aeruginosa (Imperato et al., 1977) may desulphate bile acids (Cowen et al., 1975) and thus alter the proportion of bile acids excreted as sulphates. In our study the composition of sulphated and non-sulphated faecal bile acids is similar, but LCA accounts for about $40 \%$ of total bile acid in patients taking UDCA, whereas in patients treated with CDCA it accounts for $70 \%$. Fedorowski et al. (1977b) have found results similar to ours in patients fed with $1 \mathrm{~g}$ /day of urso or cheno, whereas Makino and Nakagawa (1978) reported that LCA percentage in faeces increases to $60 \%$ of total bile acids after long-term treatment with low doses of UDCA. In the experience of Podesta et al. (1978) the percentage of total LCA was $33.7 \%$ of faecal bile acids in the controls, $24 \cdot 0-45 \cdot 7$ after UDCA, and 48.5-54.5 after CDCA. The presence of unchanged UDCA in the faeces of group I indicates the possibility that this escapes intestinal degradation, as it would seem from its high faecal radioactivity (Table 6). Like Fedorowski et al., (1977b) our results show that in patients fed with UDCA, 7-ketolithocholic acid represents about $10 \%$ of non-sulphated faecal bile acids. More unknown peaks are present on chromatograms; th zse act as dihydroxy bile acid on TLC.

\section{EXCRETION OF RADIOACTIVITY}

Total radioactivity

The patients taking CDCA had strikingly and significantly more rapid ${ }^{14} \mathrm{C}$ excretion rates than those of the UDCA group. It seems that this result does not depend on a greater faecal weight or a greater bowel frequency. The higher decay constant rate of CDCA compared with UDCA indicates a different fractional turnover rate, equivalent to the daily fractional excretion rate. The validity of the faecal excretion method for determining bile acid turnover rates is well established (Beher et al., 1966). Our result, obtained over a period of 10 days, probably depends on the different metabolic pathway of the two epimers, as demonstrated from the greater percentage and radioactivity of LCA in CDCA-treated patients.

When large quantities of CDCA are given, a new steady state is attained in which the percentage of total pool as CDCA rises to $94.5 \%$, the fractional turnover rate of CDCA, measured from specific decay curve in bile, becomes 0.59 day $^{-1}(0.27$ before therapy), and the faecal excretion of bile acids increases (Danzinger et al., 1973). UDCA given at doses of $1 \mathrm{~g} /$ day increases its proportion to only about half of total biliary bile acids. In contrast with the equivocal effect of CDCA, UDCA clearly expands the bile acid pool (Fedorowski et al., 1977b). These authors show that during UDCA feeding, $91 \%$ of the UDCA pool turned over each day, whereas our results show a higher decay of CDCA with respect to UDCA, because CDCA is more extensively degraded to poorly absorbable compounds in the intestine. In this way, more bile acids are excreted daily and the pool size is only slightly increased because of the induced inhibition of other bile acid synthesis.

\section{Distribution of radioactivity}

In Rhesus monkey more than $95 \%$ of the faecal radioactivity after ${ }^{14} \mathrm{C}$-UDCA administration was present in the fraction of LCA, whereas the activity in the UDCA fraction was less than $5 \%$; however, in this animal, the intestinal flora seems capable of carrying our the 7 $\beta$ dehydroxylation of UDCA (Ota et al., 1977). In man the intestinal metabolism of the $7 \beta O H$ group of UDCA is different from that of the $7 \alpha \mathrm{OH}$ group of CDCA (Fedorowski et al., 1977b). When ${ }^{14} \mathrm{C}$-UDCA is given intravenously to subjects fed $1 \mathrm{~g}$ /day of UDCA, the specific activity versus time decay of biliary UDCA and CDCA reveals a precursor-product relationship, whereas a relatively minute amount of CDCA is converted to UDCA. Our results demonstrate a higher LCA radioactivity in patients treated with CDCA both in the sulphated and non-sulphated fractions; in patients treated with UDCA, 7 keto LCA contains a high percentage of radioactivity $(12 \cdot 1 \%$, while about $20 \%$ of total radioactivity is present in unknown fractions. 
In conclusion, our results, although obtained during short-term therapy, show that UDCA is less degraded to poorly absorbed bile acid metabolites than is CDCA, so that small doses of UDCA may be effective in maintaining an expanded pool of bile acids.

\section{References}

Allan, R. N., Thistle, J. L., Hofmann, A. F., Carter, J. A., and Yu, P. Y. S. (1976). Lithocholate metabolism during chenotherapy for gallstone dissolution. I. Serum levels of sulphated and unsulphated lithocholates. Gut, 17, 405-412.

Beher, W. T., Beher, M. E., and Rao, B. (1966). Bile acid and cholesterol metabolism in the mouse as affected by cholestyramine. Proceedings of the Society and Experimental Biology and Medicine, 122, 881-884.

Bolin, D. W., King, R. P., and Klosterman, E. W. (1952). A simplified method for the determination of chromic oxide $\left(\mathrm{Cr}_{2} \mathrm{O}_{3}\right)$ when used as an index substance. Science, 116, 634-635.

Carey, M. C. (1978). Critical tables for calculating the cholesterol saturation of native bile. Journal of Lipid Research, 19, 945-959.

Cass, O. W., Cowen, A. E., Hofmann, A. F., and Coffin, S. B. (1975). Thin layer chromatographic separation of sulphated and non-sulphated lithocholic acids and their glycine and taurine conjugates. Journal of Lipid Research, 16, 159-160.

Cowen, A. F., Korman, M. G., Hofmann, A. F., Cass, O. W., and Coffin, S. B. (1975). Metabolism of lithocholate in healthy man. 2. Enterohepatic circulation. Gastroentero$\log y, 69,67-76$.

Danzinger, R. G., Hofmann, A. F., Thistle, J. L., and Schoenfield, L. J. (1973). Effect of oral chenodeoxycholic acid on bile acid kinetics and biliary lipid composition in women with cholelithiasis. Journal of Clinical Investigation, 52, 2809-2821.

Davignon, J., Simmonds, W. J., and Ahrens, E. H. Jr (1968). Usefulness of chromic oxide as an internal standard for balance studies in formula-fed patients and for assessment of colonic function. Journal of Clinical Investigation, 47, 127-138.

Duane, W. C., Adler, R. D., Bennion, L. J., and Sinsberg, R. L. (1975). Determination of bile acid pool in man: a simplified method with advantages of increased precision, shortened analysis time, and decreased isotope exposure. Journal of Lipid Research, 16, 155-158.

Eyssen, H. J., Parmentier, G. G., and Mertens, J. A. (1976). Sulfated bile acids in germ-free and conventional mice. European Journal of Biochemistry, 66, 507-514.

Federowski, T., Salen, G., and Mosbach, E. H. (1977a). Formation of lithocholic acid from chenodeoxycholic acid and ursodeoxycholic acid by intestinal bacteria. Gastroenterology, 73, 1220 (Abst).

Fedorowski, T., Salen, G., Colallilo, A., Tint, G. S., Mosbach, E. H., and Hall, J. C. (1977b). Metabolism of ursodeoxycholic acid in man. Gastroenterology, 73, 11311137.

Hegardt, F. G., and Dam, H. (1971). The solubility of cholesterol in aqueous solutions of bile salts and lecithin. Zeitschrift für Ernährungswissenschaft, 10, 223-233.

Imperato, T. J., Wong, C. G., Chen, L. J., and Bolt, R. J. (1977). Hydrolysis of lithocholate sulfate by Pseudomonas aeruginosa. Journal of Bacteriology, 130, 545-547.

Iser, J. H., Murphy, G. M., and Dowling, R. H. (1977). Speed of change in biliary lipids and bile acids with chenodeoxycholic acid-is intermittent therapy feasible? Gut, 18, 7-15.

Lindstedt, S. (1957). The turnover of cholic acid in man: bile acids and steroids 51. Acta Physiologica Scandinavica, 40, 1-9.

Makino, I., and Nakagawa, S. (1978). Changes in biliary lipid and biliary bile acid composition in patients after administration of ursodeoxycholic acid. Journal of Lipid Research, 19, 723-728.

Makino, I., Shinozaki, K., Yoshino, K., and Nakagawa, S. (1975). Dissolution of cholesterol gallstones by long-term administration of ursodeoxycholic acid. Japanese Journal of Gastroenterology, 72, 690-702.

Maton, P. N., Murphy, G. M., and Dowling, R. H. (1977). Ursodeoxycholic acid treatment of gallstones. Doseresponse study and possible mechanism of action. Lancet, 2, 1297-1301.

Meihoff, W. E., and Kern, F. Jr (1968). Bile salt malabsorption in regional ileitis, ileal resection, and mannitolinduced diarrhea. Journal of Clinical Investigation, 47, 261-267.

Ota, M., Matsumoto, N., Kuramoto, T., and Hoshita, T. (1977). Metabolism of bile acids. V. Metabolism of ursodeoxycholic acid in Rhesus monkey. Hiroshima Journal of Medical Sciences, 26, 253-262.

Podesta, M. T., Murphy, G. M., Sladen, G. E., and Dowling, R. H. (1978). Sulphated faecal bile acid excretion-an underestimated factor (Abstract). Clinical Science and Molecular Medicine, 54, 32 P.

Salvioli, G., Lugli, R., Salati, R., Fratalocchi, A., and Sala, B. M. (1977). Changes induced by ursodeoxycholic acid (UDCA) on the lipid composition of bile and plasma of subjects with cholesterol gallstone (CG). Cholelitholithic effect (Abstract). Digestion, 16, 345.

Stanley, M. M., and Nemchausky, B. (1967). Fecal C-14bile acid excretion in normal subjects and patients with steroid-wasting syndromes secondary to ileal dysfunction. Journal of Laboratory and Clinical Medicine, 70, 627-639.

Subbiah, M. T. R. (1973). Hyocholic acid as internal standard for quantitation of human fecal bile acids. Journal of Lipid Research, 14, 692-694.

Thomas, P. J., and Hofmann, A. F. (1973). A simple calculation of the lithogenic index of bile: expressing biliary lipid composition on rectangular coordinates. Gastroenterology, 65, 698-700.

Van Berge Henegouwen, G. P., and Hofmann, A. F. (1976). A simple batch adsorption procedure for the isolation of sulphated and non-sulphated bile acids from serum. Clinica Chimica Acta, 73, 469-474. 